\title{
Advances in soil erosion modelling through remote sensing data availability at European scale
}

Panos Panagos, Christos Karydas, Pasqualle Borrelli, Cristiano Ballabio, Katrin Meusburger

Panos Panagos, Christos Karydas, Pasqualle Borrelli, Cristiano Ballabio, Katrin Meusburger, "Advances in soil erosion modelling through remote sensing data availability at European scale," Proc. SPIE 9229, Second International Conference on Remote Sensing and Geoinformation of the Environment (RSCy2014), $92290 \mathrm{l}$ (12 August 2014); doi: 10.1117/12.2066383

Event: Second International Conference on Remote Sensing and Geoinformation of the Environment (RSCy2014), 2014, Paphos, Cyprus 


\title{
Advances in soil erosion modelling through remote sensing data availability at European scale
}

\author{
Panos Panagos*a ${ }^{*}$, Christos Karydas ${ }^{\mathrm{b}}$, Pasqualle Borrelli $^{\mathrm{a}}$, Cristiano Ballabio $^{\mathrm{a}}$, Katrin Meusburger ${ }^{\mathrm{c}}$ \\ ${ }^{a}$ European Commission, Joint Research Centre, Institute for Environment and Sustainability, Via E. \\ Fermi 2749, I-21027 Ispra, ITALY; ${ }^{\mathrm{b}}$ Aristotle University of Thessaloniki, Lab of Forest \\ Management and Remote sensing, Thessaloniki, GREECE; ${ }^{\mathrm{c}}$ Environmental Geosciences, \\ University of Basel, Bernoullistrasse 30, 4056 Basel, SWITZERLAND.
}

*panos.panagos@jjrc.ec.europa.eu ; phone +390332 785574; fax +390332 783694; http://eusoils.jrc.ec.europa.eu

\begin{abstract}
Under the European Union's Thematic Strategy for Soil Protection, the European Commission's Directorate-General for the Environment (DG Environment) has identified the mitigation of soil losses by erosion as a priority area. Policy makers call for an overall assessment of soil erosion in their geographical area of interest. They have asked that risk areas for soil erosion be mapped under present land use and climate conditions, and that appropriate measures be taken to control erosion within the legal and social context of natural resource management. Remote sensing data help to better assessment of factors that control erosion, such as vegetation coverage, slope length and slope angle. In this context, the data availability of remote sensing data during the past decade facilitates the more precise estimation of soil erosion risk.

Following the principles of the Universal Soil Loss Equation (USLE), various options to calculate vegetative cover management (C-factor) have been investigated. The use of the CORINE Land Cover dataset in combination with lookup table values taken from the literature is presented as an option that has the advantage of a coherent input dataset but with the drawback of static input. Recent developments in the Copernicus programme have made detailed datasets available on land cover, leaf area index and base soil characteristics. These dynamic datasets allow for seasonal estimates of vegetation coverage, and their application in the G2 soil erosion model which represents a recent approach to the seasonal monitoring of soil erosion. The use of phenological datasets and the LUCAS land use/cover survey are proposed as auxiliary information in the selection of the best methodology.
\end{abstract}

Keywords: MODIS, seasonality, C-factor, Vegetation coverage, G2, Biophysical parameters, RUSLE

\section{INTRODUCTION}

Erosion by running water has been identified as the most severe hazard with regard to the protection of soil in Europe ${ }^{1}$ By removing the most fertile topsoil, erosion reduces soil productivity. Where soils are shallow, this leads to a progressive and ultimately irreversible loss of natural farmland, and in vulnerable areas is a major process of desertification ${ }^{2}$.

Globally, soil erosion has been addressed as one of the most critical soil degradation hazards. It has been found that almost $12 \%$ of the European territory, accounting for almost 115 million hectares, is subject to soil erosion. The financial cost impact of erosion has been calculated as being several billion Euros ${ }^{1}$.

New developments in soil policy at the European level, which have come about with the introduction of the thematic strategy for the protection of soils and the establishment of the European Soil Data Centre (ESDAC) ${ }^{3}$, put in place a reporting mechanism from Member States to the European Union with the ultimate goal of assessing soil conditions.

Soil erosion monitoring is very costly and is usually limited to a number of plot sites. Therefore, a large number of models have been developed to estimate soil erosion by water at different scales ${ }^{4}$. According to Karydas et al. (2014), who reviewed 82 erosion models, the most widely applied empirical soil erosion models are the Universal Soil Loss

Second International Conference on Remote Sensing and Geoinformation of the Environment (RSCy2014), edited by Diofantos G. Hadjimitsis, Kyriacos Themistocleous, Silas Michaelides, Giorgos Papadavid,

Proc. of SPIE Vol. 9229, 92290I · (C) 2014 SPIE · CCC code: 0277-786X/14/\$18 · doi: 10.1117/12.2066383 
Equation (USLE) ${ }^{5}$, and its more recent version, the Revised-USLE (or RUSLE), introduced by Renard et al ${ }^{6}$. Remote sensing data are contributing in estimating the erosion risk factors such as vegetation coverage, slope length and slope angle. In this study, the focus is on the assessment of vegetation coverage, as the other factors can be calculated by using standard equations.

\subsection{USLE model and Vegetation Coverage}

In the USLE (and the subsequent RUSLE) model, the vegetation coverage (the C-factor) is dimensionless (unitless) and represents the influence of terrain cover, land management and cropping in mitigating soil erosion. Among the six different erosion factors, the cover-management factor and the support practices are probably the most important ones as they can be influenced by human activities. The other erosion factors (such as rainfall erosivity, soil erodibility (incorporating stoniness), slope steepness and slope length) are independent of human activities.

The two factors that can prevent soil erosion are vegetation cover (C-factor) and management practices (P-factor). The removal of vegetation cover can accelerate soil erosion at an exponential scale and thus increase sediment yield significantly ${ }^{7}$. The $\mathrm{C}$-factor is estimated using a number of methodologies, taking as input a) land Cover indexes, b) remotely sensed data, c) vegetation indexes, and d) field observations.

Among the soil erosion factors, vegetation coverage (C-factor) and rainfall erosivity (R-factor) are the two dynamic factors that change over the course of a year. Time series of vegetation datasets can be used to calculate the seasonal Cfactor throughout a given year. The availability of remote sensing data allows for the identification of high risk seasons when high rainfall intensity is combined with low vegetation coverage. Therefore, remote sensing data are very appropriate to capture the spatial and temporal variability of the C-factor.

\subsection{Available satellites for global vegetation coverage}

There is currently a plethora of satellite sensors for mapping vegetation patterns and other parameters related to land cover and land use at low to moderate resolutions. NOAA-AVHRR is a satellite sensor at 1.1-km resolution, designed for defining hydrologic, oceanographic, and meteorological parameters, with daily coverage, available since 1981. Another coarse resolution satellite sensor is SPOT-VGT, at 1-km resolution, designed to provide daily vegetation indices since 1998. At 300-m resolution, the ENVISAT MERIS sensor produced regular standardised biophysical parameter layers over Europe for about 10 continuous years (2002-2012) under the GMES (now Copernicus) initiative, but is no longer operational. Launched in May of 2013, the Proba-V sensor provides multispectral images at 333-m resolution to study the evolution of the vegetation cover on a daily and global basis (' $\mathrm{V}$ ' stands for vegetation). This mission extends the dataset of the SPOT-VGT sensor, flown as a secondary payload aboard SPOT-4 and SPOT-5 satellites, which will be retired by 2015. TERRA/MODIS, with $250-\mathrm{m} / 500-\mathrm{m} / 1-\mathrm{km}$ resolution, covers the Earth's surface on a daily basis, capturing data in 36 spectral bands ranging in wavelength from $0.4 \mu \mathrm{m}$ to $14.4 \mu \mathrm{m}$, since 1999 . Among radar systems which enable us to acquire imagery regardless of the weather, RADARSAT-2 has been one of the most powerful technical advancements for global environmental monitoring and resource management mapping since 2007.

For medium- to high-resolution spatial scales, the launch of Landsat-8 in 2013 by NASA was an important development, as it continues a very long times series of global satellite image acquisition that began in 1982. Landsat-8 carries an Operational Land Imager (OLI) and Thermal Infrared Sensor (TIRS). The new sensors have additional spectral bands (in the deep blue and middle infrared wavelengths) which, together with a new Quality Assurance band, provide enhancements over prior Landsat instruments. Starting from 2014, the European Space Agency (ESA) is planning to launch a series of new satellite sensors (radar and optical) for land and ocean monitoring. Sentinel-1 will be composed of two polar-orbiting satellites operating day and night, which will perform Radar imaging. The objective of Sentinel-2 is to provide optical imagery at $10-\mathrm{m} / 20-\mathrm{m} / 60-\mathrm{m}$ resolution for monitoring vegetation, soil and water cover, inland waterways and coastal areas, at a revisit time of 2 to 5 days. Sentinel-2 satellites will routinely deliver high-resolution optical images globally, providing enhanced continuity of SPOT- and Landsat-type data. 


\subsection{Objectives}

This paper presents various options for the spatio-temporal estimation of the C-factor. As a review of existing or potential technologies, it aims to identify the most appropriate methodologies applicable at the European scale. Soil erosion modelling at European scale is advancing through the availability of Lad Use/Cover Area frame Survey (LUCAS) soil data which allows for soil erodibility mapping at 500-m resolution ${ }^{8}$, the availability of national soil erosion estimates ${ }^{9}$ and the advancing assessment of rainfall erosivity dataset based on sub-hourly rainfall data ${ }^{10}$. However, the potential of new remote sensing data for estimating C-factor at European scale still needs to be explored. The criteria for selecting the best methodology for the development of the $\mathrm{C}$-factor at the European scale are:

a) Extent: The methodology should be applied at the European scale.

b) Scale: The produced dataset should have a resolution of $1 \mathrm{~km}$ grid cell.

c) Reproducibility and data availability: The input attributes are not restricted by copyright and are continuously updated.

d) Seasonal effect: data outputs are produced for different time steps (e.g. monthly) of the year.

Together with the seasonal rainfall erosivity layers, the selection of the best methodology will allow for developing seasonal erosion outputs at the European scale. The C-factor maps must match the rainfall erosivity time-step (e.g. monthly).

\section{METHODS TO PARAMETERIZE THE IMPACT OF VEGETATION COVERAGE ON SOIL EROSION}

According to the metadata of the soil erosion estimates data collection from European countries (EIONET network), most countries use the CORINE Land Cover dataset as input to estimate the C-factor'. In some limited cases, countries had their own land cover indexes at better scale, while phenological data and crop statistics have also been used in certain cases.

\subsection{Mapping C-factor based on CORINE Land Cover (CLC)}

In 1985, the European Commission launched the CORINE (Coordination of Information on the Environment) programme. The two main objectives of the CORINE Land Cover (CLC) project were (a) to provide reliable quantitative data on land cover across Europe, and (b) to develop one complete spatial land cover dataset covering the EU Member States (MS) plus several other European and North African countries. The CORINE datasets ${ }^{11}$ were developed by image analysis and digitalisation of Landsat photos in a GIS environment. CORINE Land Cover datasets from 1990, 2000, and 2006 have been used to calculate the C-factor at the European level. The datasets contain homogeneous data on land cover areas which are provided in vector format (as polygons). The CORINE Land Cover datasets were established following harmonised procedures based on a common classification system, and can therefore be easily compared ${ }^{12}$. Data are classified in 44 land-cover classes, which are grouped into three hierarchical levels. Their nominal scale is 1:100,000 with a minimum mapping unit of 25 ha and a change detection threshold of 5 ha. In the CORINE Land Cover dataset, the minimum mapping unit size (25 ha) underestimates the landscape diversity trends ${ }^{13}$.

For each land use type, the $\mathrm{C}$-factor was estimated according to the literature findings ${ }^{6},{ }^{14}$. The land use classification is used in combination with lookup tables from the literature to plot the vegetation coverage maps. The $\mathrm{C}$-factor for arable lands was set to 0.3 and to an average C-factor of 0.01 for grasslands, while dense forests had the minimum C-factor of 0.001. Dense shrublands have a $\mathrm{C}$-factor value of 0.01 , while sparse shrublands have been assigned a value of 0.10 . The permanent crops have values between 0.1 and 0.3 . Urban areas, bare rocks and mountain peaks have the value 0 which results in zero erosion for these areas. This approach has been successfully applied in many European areas: Slovakia ${ }^{15}$, southern Italy ${ }^{16}$, Tuscany ${ }^{17}$, southeastern Spain ${ }^{18}$ and a comparative analysis in Greece-France-Belgium-Portugal ${ }^{19}$.

Using the above mentioned literature C-factor and the CORINE Land Cover datasets ${ }^{11}$, a C-factor map was produced at the European level (Fig. 1). Lower C-factor values correspond to a lower risk of soil erosion. The arable lands show the highest $\mathrm{C}$-factor values. 


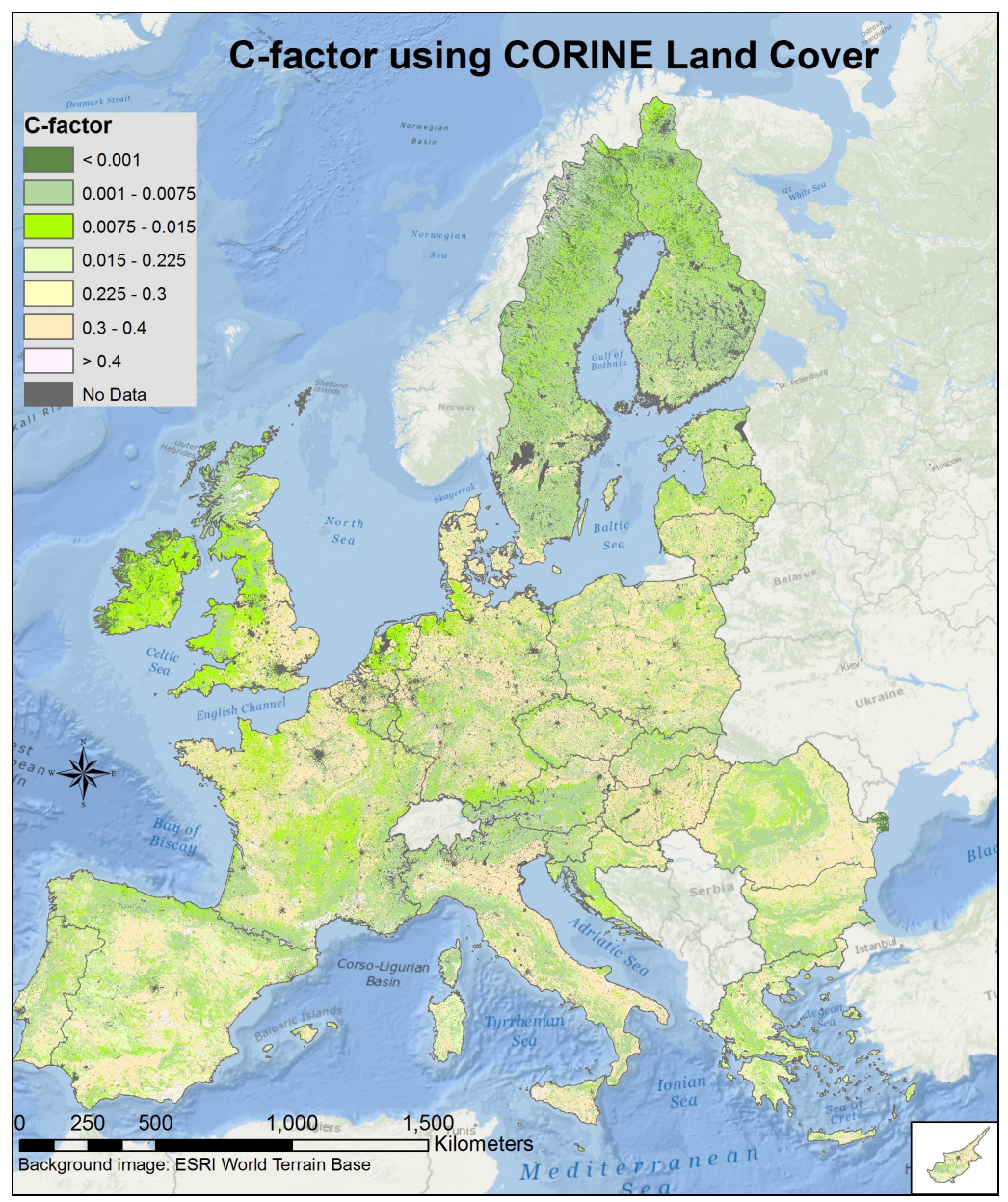

Figure 1. European C-factor map based on CORINE Land Cover data.

\subsection{Seasonal mapping based on remote sensing derived biophysical attributes (MERIS)}

Bearing in mind the importance of vegetation in erosion processes, the general trend is to identify available remote sensing datasets at the European scale which can provide monthly vegetation indexes. The availability of Medium Resolution Imaging Spectrometer (MERIS) satellite data facilitated the development of biophysical parameters at a resolution of 1-km grid cell for the whole of Europe, within the context of the Copernicus programme. The availability of those biophysical parameter layers encourages the development of dynamic vegetation indices.

The biophysical attributes Fraction of Soil (FSoil) and Leaf Area Index (LAI) derived from MERIS data have been used in the development of the G2 erosion model and its first application in the Strymonas catchment area ${ }^{20}$ located in the cross border between Greece and Bulgaria. The C-factor, which was renamed the V-factor in the G2 model ('vegetation retention'), is given by the following equation:

$$
V=\frac{\text { FSoil }+\frac{\text { FSoil }}{L A I+1}}{2}
$$




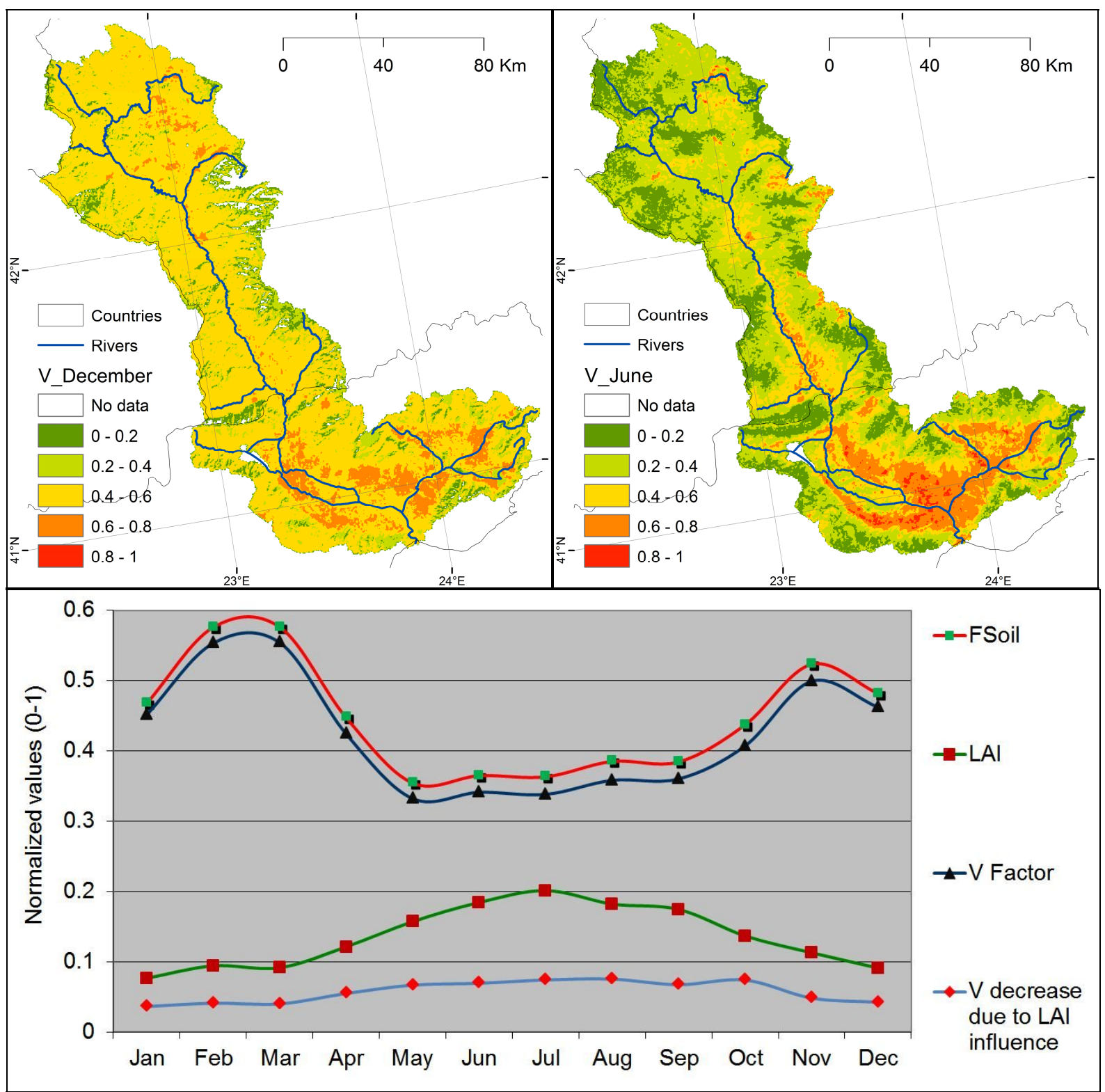

Figure 2. V-factor (Vegetation retention) in the Strymonas catchment area in two different months: December (upper left), June (upper right) and the V-factor distribution during the year (bottom).

The objective of the application of equation (1) was to link vegetation coverage proportionally to the FSoil, taking into consideration the fact that bare soil $(\mathrm{FSoil}=1)$ is unprotected from erosion. The LAI expresses the effect of vegetation density on the unit area and is inversely proportional to the $\mathrm{V}$-factor. Using equation (1), monthly vegetation coverage layers were developed (Fig. 2). The vegetation coverage in December is more homogeneous in the study area, with the majority of V-factor values ranging between 0.4-0.8. Conversely, the vegetation coverage in June shows extreme patterns as the northern part of the catchment has the lowest V-factor, mainly due to full canopy and forest density during this period. Contrary to the forest area in the north, the arable lands in the south have the highest V-factor as most of the crops are harvested in June. The dynamics of vegetation development have been captured with the proposed methodology as they greatly coincide with the crop growth in this Mediterranean catchment (large parts of bare soil or sparse vegetation during October - March and vegetation growth during May - July). 
The effect of LAI proved to be insignificant, as the maximum decrease of $\mathrm{V}$-factor was $8 \%$ on average during the period of canopy growth (July-August). The effect of LAI was minimal during the winter period (3\% average decrease in the vegetation factor) (Fig. 2). Considering the small effect of LAI, the G2 model was revised by replacing LAI with a Land Use (LU) parameter.

In the seasonal monitoring of soil erosion in Crete with the revised G2 model ${ }^{21}$, the V-factor was used as the denominator in order to reflect the protective effect of vegetation against soil erosion. This change, which was a part of an overall G2 model revision, implied that lower V-factor values represent an absence of vegetation ( $\mathrm{V}=1$ for bare soil); therefore, the change had no effect on the potential erosion value (in this case the potential erosion is considered to be that occurring on bare soil). On the contrary, high V-factor values correspond to dense vegetation supported by protective management practices. $\mathrm{V}$ is introduced as a dynamic factor in the estimation of soil erosion, by combining inputs from time series of vegetation layers and a constant empirical land use (LU) parameter:

$$
\mathrm{V}_{\mathrm{LU}}=\mathrm{e}^{(\mathrm{LU} * \mathrm{Fcover})}
$$

The FCover layer is complementary to the FSoil layer in their normalised form (i.e. FCover=1-FSoil), whereas the LU attribute is an empirical land use parameter derived from expert knowledge applied in CORINE classes (corresponding to the Gavrilovic empirical tables). This empirical attribute can differentiate the influence of diverse land uses on land with the same vegetation coverage. According to the USLE empirical tables, the C-factor is reduced in a non-linear way against vegetation growth and tillage practices. The exponential reduction of the V-factor due to an increase of FCover is met by the development of the exponential function (2).

The month-step V-layers (called 'vegetation retention' layers in the G2 model), in combination with corresponding timestep R-factor layers, contribute to integrated spatio-temporal soil erosion monitoring (Fig. 3).
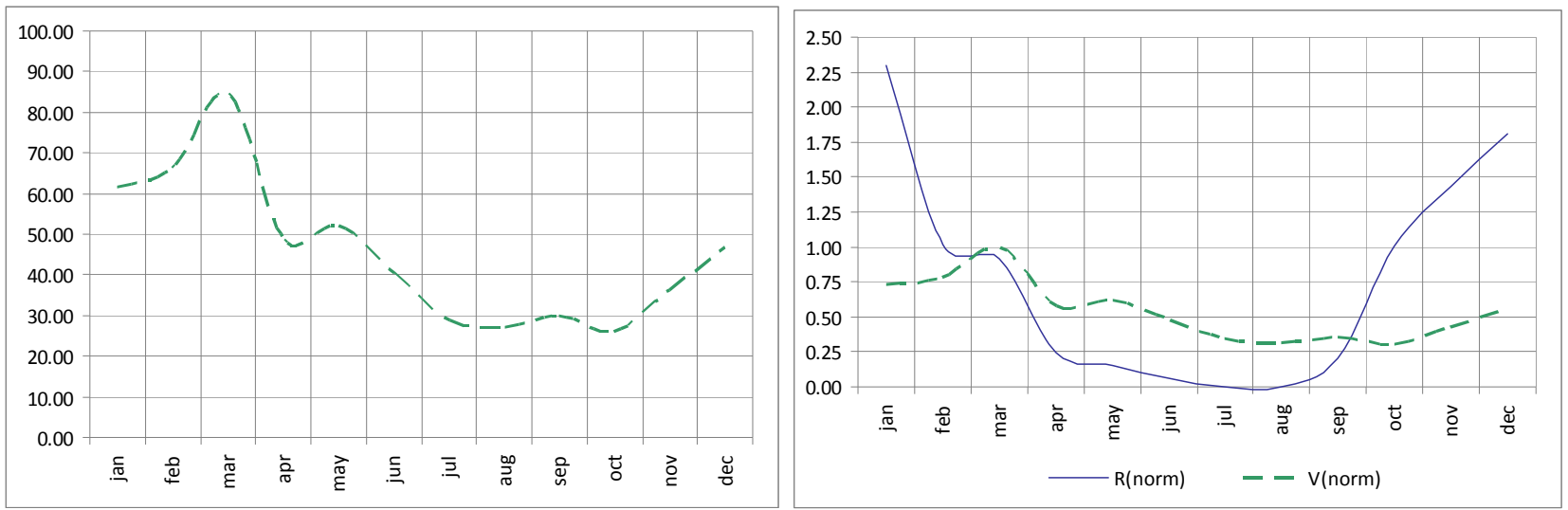

Figure 3. Temporal distribution of V-factor and R-factor in Crete; left: V-values indicate how many times the potential erosion risk is reduced due to vegetation and land use management; right: Normalised curves of Monthly $\mathrm{R}$ and $\mathrm{V}$ factors.

In some cases, there can be spatial gaps in the layers of biophysical parameters due to presence of clouds (especially on the mountain peaks). The temporal integration of layers from recent dates or from additional past years could resolve the problem of mapping a complete surface. According to the derived V-layers, it seems that the western part of Crete has almost double the vegetation protection (on average) compared to the eastern part (Fig. 4). 

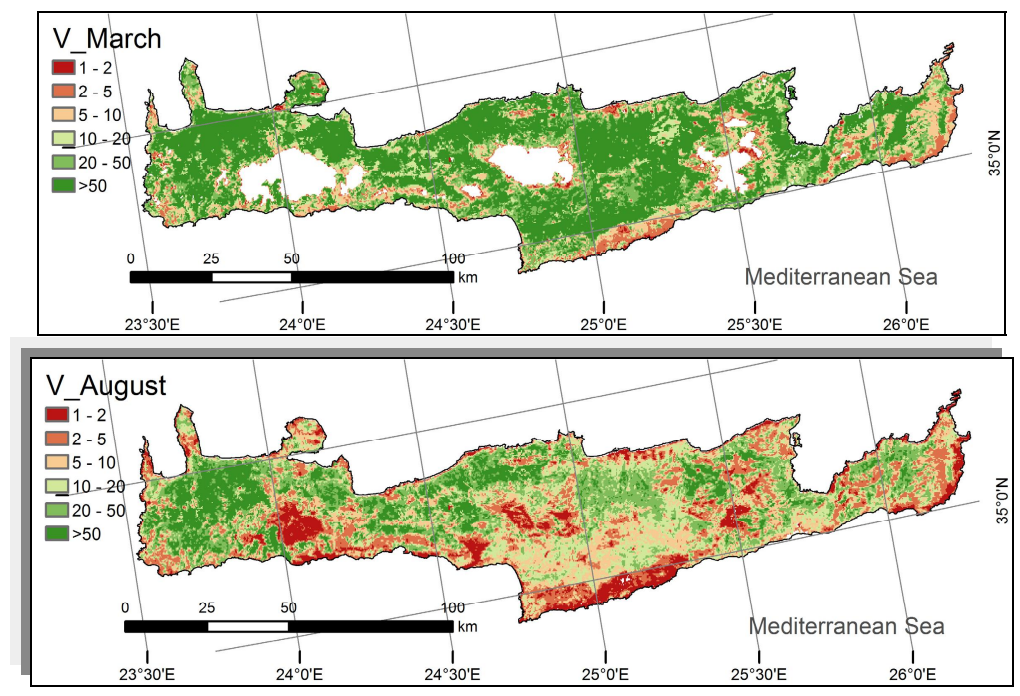

Figure 4. V-factor (protective effect of vegetation against erosion) in Crete in two months: March (upper), August (lower).

\subsection{Seasonal mapping based on remote sensing derived phonological data (MODIS)}

MODIS MOD13Q1 Enhanced Vegetation Index (EVI) data ${ }^{22}$ are dedicated to enabling the assessment of crop patterns in the European Union. EVI allows for the identification of the spatio-temporal distribution of crop phenology across continental Europe. The output results are dynamic 'land use layers' which can be used for the seasonal monitoring of vegetation coverage in erosion models (Fig. 5).

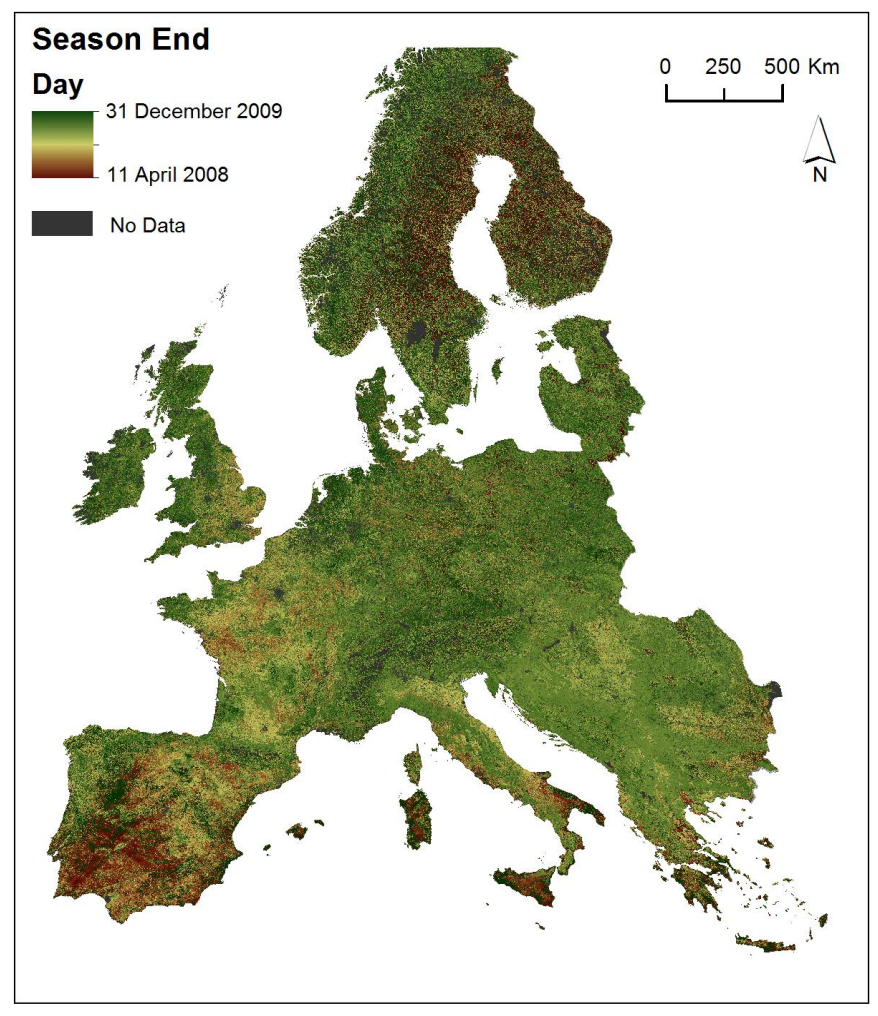

Figure 5. Phenological map of the crop seasonality. 
The 12-year MODIS time series for Europe will be processed in order to develop phenological metrics. The results will be validated against the Land Use/Land Cover (LUCAS) dataset. It is important to classify different cops using both the MODIS data and available statistical data. This will allow for a more precise (depending on the crop) and dynamic predictions of vegetation coverage.

\subsection{Land Use/Cover Area frame Survey (LUCAS)}

LUCAS is an in-situ survey, which means that the data are gathered through direct field observations. The aim of the LUCAS survey is to gather fully harmonised data on land use/cover and their changes over time in European Union (EU) countries. It is compatible with existing land cover/use systems (e.g. FAO, NACE and Farm Structure Survey) and it fulfils the specifications of the European INSPIRE standardisation initiative for land cover and land use. The LUCAS nomenclature has evolved over the years (2001/2003/2006/2009/2012), but its fundamental aspects have remained. In the LUCAS 2012 survey, almost 270,000 geo-referenced points were visited by more than 700 field surveyors.

LUCAS points are plotted on a regular grid of $2,828 \mathrm{~m} \mathrm{x} \mathrm{2,828} \mathrm{m}$. However, the visited points can deviate from the designed location, due to partial inaccessibility. The compiled LUCAS database includes information on primary and secondary land cover/use. The LUCAS nomenclature has a three-level hierarchy, with 57 classes (around 35 classes of crops), but differs from CORINE nomenclature. In the past, LUCAS has been used successfully for the validation of the CORINE $2000^{23}$ dataset by the European Environmental Agency (EEA). In a similar way, the LUCAS database currently available in EUROSTAT ${ }^{24}$ can be used for the validation of the land cover classes extracted from satellite images and for the better calibration of the vegetation coverage factor used in soil erosion models.

\section{DISCUSSION}

The application of CORINE methodology has the drawback of assigning C-factor values in a static way. This is evident in arable lands where the soil can be prone to erosion due to absence of vegetation in late autumn, but where crop development during spring is a protective factor against erosion. The seasonal crop dynamics are not accounted for in the distribution of $\mathrm{C}$-factor during the whole year. The seasonal development of crops and its large bias between northern and Mediterranean countries is hardly taken into account in this methodology. The application of different monthly indices is not appropriate for pan-European scale application as crop growth varies significantly between different areas of Europe.

New remote sensing products with short repetition times and spatial resolutions between $300 \mathrm{~m}$ and $1 \mathrm{~km}$ offer a solution to this problem. For instance, the great potential of biophysical parameters (derived from MERIS) has been demonstrated by their application in the estimation of the C-factor. The first application of the G2 soil erosion model in Strymonas and the use of combined FSoil and LAI biophysical parameters was rather successful in predicting the seasonal effect of vegetation, but underestimated the effect of LAI (actually, Fcover and LAI were found to be highly interdependent). The modified approach followed in Crete improved the original G2 methodology, by quantitatively introducing the effect of land use on vegetation and soil. However, as the exact LU value is picked up from a range of values based on expert knowledge, it can still be considered as being partially subjective.

The LUCAS dataset could be of great potential for point observations and ground trothing of remote sensing products at European scale. Those point observations with a high density can be used in correlation with remote sensing data (SRTM) to interpolate the vegetation coverage and develop C-factor maps ${ }^{26}$. Geostatistical methods such as inverse weighted distance or even more sophisticated ones such as cubist regression ${ }^{8}$ have been applied in the past for the development of the K-factor within Europe.

The alternative option of identifying the month (or period) which is best suited to estimate vegetation coverage was not taken into account as the objective here is to develop datasets for all the seasons of the year. The use of the Normalised Difference Vegetation Index (NDVI) was not considered in the present study as this is proved to correlate poorly with vegetation attributes ${ }^{25}$ due to the effect of soil reflectance and vitality of vegetation. 


\section{CONCLUSIONS AND OUTLOOK}

Using the MODIS sensor with 36 spectral bands, daily-acquired imagery distributed free of charge has an enormous potential use in environmental models such as those regarding soil erosion. The MODIS-derived products advance the spatial and temporal monitoring of biophysical characteristics of vegetation across large geographic areas such as the whole of Europe.

The problem of seasonal C-factor estimation (e.g. on a month-step) has been raised a long time ago, but only recently has been managed in an integrative way by the G2 erosion model. In the past, efforts were based either on static approaches to calculating C-factor, on ad-hoc solutions, or were eliminated in small study sites. The G2 model follows the same perspective with the original USLE empirical approach, but on a larger geographic scale. Congruent to USLE, the Cfactor effect is parameterized in two sub-parameters: vegetation coverage and management practices.

Vegetation coverage has a dynamic dimension, whereas land use management is mostly static -at least within a period of one year. The G2 model has used MERIS data as input for vegetation coverage, and CORINE Land Cover data for the land use effect. In the future, the required vegetation properties can be provided by biophysical parameter layers derived from satellite data, such as TERRA/MODIS or PROBA-V, which will replace MERIS and SPOT-VGT. Current efforts are also dedicated to the improvement of the land use effect, in terms of spatial accuracy and reliability, with Land Use (LU) parameter selection of the G2 model relying on purely objective judgments derived from completely quantified and harmonised land use geodatabases.

\section{ACKNOWLEDGMENTS}

The authors would like to thank Gráinne Mulhern for revision of the article from a linguistic point of view.

\section{REFERENCES}

[1] EC, 2006. Communication from the Commission to the Council, the European Parliament, the European Economic and Social Committee of the Regions, Thematic Strategy for Soil Protection, (COM(2006) 231 final).

[2] Kirkby M.J., Irvine B.J., Jones R.J.A., Govers G., Boer M., Cerdan O., Daroussin J., (...), Van Lynden G. The PESERA coarse scale erosion model for Europe. I. - Model rationale and implementation (2008) European Journal of Soil Science, 59 (6), pp. 1293-1306.

[3] Panagos, P., Van Liedekerke, M., Jones, A. \& Montanarella, L. European Soil Data Centre (ESDAC): Response to European policy support and public data requirements (2012) Land Use Policy, 29 (2), pp. 329-338.

[4] Karydas CG, Panagos P, Gitas IZ. A classification of water erosion models according to their geospatial characteristics. International Journal of Digital Earth, Vol. 7, 3, 2014, pp. 229-250.

[5] Wischmeier WH, Smith DD 1978: Predicting Rainfall Erosion Losses-A Guide for Conservation Planning. Agriculture Handbook 537. U.S. Department of Agriculture, Washington, DC.

[6] Renard KG, Foster GR, Weessies GA, McCool DK 1997: Predicting soil erosion by water: a guide to conservation planning with the revised universal soil loss equation (RUSLE). In Agriculture Handbook 703, Ed. Yoder DC. U.S. Department of Agriculture, Washington, DC.

[7] Vanacker, V., et al.. Restoring dense vegetation can slow mountain erosion to near natural benchmark levels. (2007) Geology, 35, 303-306.

[8] Panagos, P., Meusburger, K., Ballabio, C., Borrelli, P., Alewell, C. (2014) Soil erodibility in Europe: A highresolution dataset based on LUCAS. Science of Total Environment, 479-480 (2014) pp. 189-200

[9] Panagos, P., Meusburger, K., Van Liedekerke, M., Alewell, C., Hiederer, R., Montanarella, L. 2014. Assessing soil erosion in Europe based on data collected through a European Network. Soil Science and Plant Nutrition (in Press). DOI: 10.1080/00380768.2013.835701

[10] Meusburger, K., Steel, A., Panagos, P., Montanarella, L., Alewell, C. (2012) Spatial and temporal variability of rainfall erosivity factor for Switzerland. Hydrology and Earth System Sciences, 16, 167-177, 2012

[11] CLC, 2014. CORINE Land cover dataset for 1990 - 2000 - 2006. Available at: http://www.eea.europa.eu/dataand-maps $/$ data\#c5 $=$ all \&c1 $1=$ natural\&c17 $=\& \mathrm{c} 0=5 \& \mathrm{~b} \_$start $=0 \quad$ (Accessed 02/03/2014). 
[12] Neumann K., Herold M., Hartley A., Schmullius C., 2007. Comparative assessment of CORINE2000 and GLC2000: Spatial analysis of land cover data for Europe. International Journal of Applied Earth Observation and Geoinformation, 9 (4), 425-437.

[13] Saura S., 2002. Effects of minimum mapping unit on land cover data spatial configuration and composition. International Journal of Remote Sensing, 23, 4853-4880.

[14] NS Department of Agriculture and Fisheries, 2001. Green Plan Soil and Water Conservation: Combining the USLE and a GIS for Planning Crop Rotations.

[15] Cebecauer, T. and Hofierka, J.: The consequences of land-cover changes on soil erosion distribution in Slovakia, Geomorphology, 98, 187-198, 2008.

[16] Diodato, N., Fagnano, M., and Alberico, I.: Geospatial and visual modeling for exploring sediment source areas across the Sele river landscape, Italy, Italian Journal of Agronomy, 6(2), 2011.

[17] Marker, M., Angeli, L., Bottai, L., Costantini, R., Ferrari, R., Innocenti, L., and Siciliano, G.: Assessment of land degradation susceptibility by scenario analysis: A case study in Southern Tuscany, Italy, Geomorphology, 93, 120-126, 2008

[18] de Vente J., Poesen J., Govers G., Boix-Fayos C. The implications of data selection for regional erosion and sediment yield modelling (2009) Earth Surface Processes and Landforms, 34 (15) , pp. 1994-2007.

[19]Bakker M.M., Govers G., van Doorn A., Quetier F., Chouvardas D., Rounsevell M.. The response of soil erosion and sediment export to land-use change in four areas of Europe: The importance of landscape pattern (2008) Geomorphology, 98 (3-4) , pp. 213-226.

[20] Panagos, P., Karydas, C.G., Gitas, I.Z., Montanarella, L. Monthly soil erosion monitoring based on remotely sensed biophysical parameters: a case study in Strymonas river basin towards a functional pan-European service. International Journal of Digital Earth (2012) Vol. 5, Iss. 6, 2012, pp. 461-487.

[21] Panagos, P., Karydas C.G., Ballabio, C., Gitas, I.Z. Seasonal monitoring of soil erosion at regional scale: An application of the G2 model in Crete focusing on agricultural land uses. International Journal of Applied Earth Observation and Geoinformation (2014) Volume 27, Part B, April 2014, pp. 147-155

[22] Huete, A., Didan, K., Miura, T., Rodriguez, E. P., Gao, X., \& Ferreira, L. G. (2002). Overview of the radiometric and biophysical performance of the MODIS vegetation indices. Remote sensing of environment, 83(1), 195-213.

[23] Gallego J., Bamps C. Using CORINE land cover and the point survey LUCAS for area estimation (2008) International Journal of Applied Earth Observation and Geoinformation, 10 (4) , pp. 467-475.

[24] EUROSTAT, 2014. European Commission, Land Use/cover statistics (LUCAS). Available at: http://epp.eurostat.ec.europa.eu/portal/page/portal/lucas/data/database (Accessed 10/3/2014)

[25] De Jong, S.M., 1994. Derivation of vegetative variables from a Landsat TM image for modelling soil erosion. Earth Surface Processes and Landforms, 19, 165-178.

[26] Vrieling A. Satellite remote sensing for water erosion assessment: A review. Catena (2006), 65 (1), pp. 2-18. 